\title{
Sociodemographic and clinical characteristics of persons who experienced spontaneous hepatitis C viral clearance
}

Mabel Michille Kimble ${ }^{1}$, Marjan Javanbakht ${ }^{2}$, Kara W. Chew $^{1}$, Chrysovalantis Stafylis ${ }^{1 *}$ DD, Di He${ }^{2}$, Samantha Ramirez ${ }^{3}$, Yeonsoo Baik2, Sammy Saab ${ }^{3}$ and Jeffrey D. Klausner ${ }^{1,2}$

\begin{abstract}
Background: In the United States Hepatitis C virus (HCV) viral clearance is estimated to range between 20 and $30 \%$. The objective of this study was to estimate the frequency of HCV clearance and identify correlates of viral clearance among patients newly identified as HCV antibody positive in a large urban health system in Los Angeles, California.

Methods: We identified patients between November 2015 and September 2017 as part of a newly implemented HCV screening and linkage-to-care program at University of California Los Angeles (UCLA) Health System. All patients were eligible for screening, though there were additional efforts to screen patients born between 1945 and 1965. We reviewed Medical records to categorize anti-HCV antibody positive patients as having spontaneously cleared HCV infection (HCV RNA not detected) or not (HCV RNA detected). We excluded those with a prior history of anti-HCV positivity or history of HCV treatment. We compared differences between those with and without detectable HCV RNA using chi-square test, Fisher's exact test, and t-test as appropriate. We assessed factors associated with HCV clearance using logistic regression analysis.
\end{abstract}

Results: Among the 320 patients included in this study, 56\% were male. Baby boomers (52-72 years of age) comprised the single largest age group (62\%). We found spontaneous HCV clearance in 58\% $(n=185)$. HCV viral clearance was slightly higher among women as compared to men (63\% vs. $53 \% ; p$ value $=0.07)$ and varied by race/ ethnicity: clearance among Blacks/African Americans was 37\% vs. 58\% among whites ( $p$ value $=0.02$ ). After adjusting for age, race/ethnicity, and sex we found that those diagnosed with chronic kidney disease had a tendency of decreased HCV viral clearance (adjusted OR $=0.34$; 95\% Cl 0.14-1.03).

Conclusion: Of those patients newly identified as anti-HCV positive, $58 \%$ had cleared HCV virus, while the rest showed evidence of active infection. In addition, we found that clearance varied by race/ethnicity and clinical characteristics.

Keywords: Hepatitis C, Epidemiology, Spontaneous clearance

\footnotetext{
* Correspondence: cstafylis@mednet.ucla.edu

${ }^{1}$ Department of Medicine, Division of Infectious Diseases, University of

California Los Angeles, 10920 Wilshire Blvd. Suite 350 Room 40, Los Angeles,

CA 90024, USA

Full list of author information is available at the end of the article
}

(c) The Author(s). 2019 Open Access This article is distributed under the terms of the Creative Commons Attribution 4.0 International License (http://creativecommons.org/licenses/by/4.0/), which permits unrestricted use, distribution, and reproduction in any medium, provided you give appropriate credit to the original author(s) and the source, provide a link to the Creative Commons license, and indicate if changes were made. The Creative Commons Public Domain Dedication waiver (http://creativecommons.org/publicdomain/zero/1.0/) applies to the data made available in this article, unless otherwise stated. 


\section{Background}

In the United States the proportion of those with spontaneous hepatitis $\mathrm{C}$ virus (HCV) clearance varies between studies. Historically it's been estimated that clearance occurs in 15-20\% of patients infected with HCV [1]. Recent data suggest that spontaneous clearance of $\mathrm{HCV}$ infection in the absence of treatment is higher than previously estimated [1-3]. In one of the first studies to estimate spontaneous HCV clearance defined on the basis of HCV RNA assessments within 24 months of diagnosis - the frequency of clearance was $26 \%$ [4].

Why certain groups clear HCV infection without antiviral treatment remains unclear [5-8]. Studies suggest host innate immune system or genetic factors may play a role [9-11]. Factors such as sex, race/ethnicity, young age, HLA type, IL28B genotype, HIV-infection status, and chronic hepatitis $B$ infection are known to affect clearance [2, 4, 10, 12-21]. However, most studies on spontaneous HCV viral clearance are limited by small sample size, heterogeneous definitions of cases, and study inclusion criteria, including study populations that are limited to high-risk groups such as illicit substance users and men who have sex with men $[4,7,12,13]$. Little is known about screening populations, in particular baby boomers, a birth cohort known to have increased risk of $\mathrm{HCV}$ infection [22-25]. Our aim was to identify the frequency of and factors associated with spontaneous HCV clearance among patients participating in a hepatitis $C$ screening program at a large urban health system in Los Angeles, California.

\section{Methods}

\section{Study population}

Patients seeking primary care services at UCLA Health were screened for $\mathrm{HCV}$ infection between November 2015 and September 2017. As per the US preventive task force recommendations for HCV screening, testing was initiated with the HCV antibody test (anti HCV Ab) and was targeted to high risk groups, as well as one-time testing of adults born between 1945 and 1965 regardless (regardless of their HCV risk factors) [26]. The program has been previously described [27]. Briefly, a structural intervention using electronic medical record prompts was implemented to promote $\mathrm{HCV}$ screening among patients seeking care at UCLA health. The electronic medical record (EMR) prompts were specifically developed to not only capture high risk groups for $\mathrm{HCV}$ infection, who had never tested for HCV, but also to target screening towards "baby boomers" (i.e., those born between 1945 and 1965) without any prior history of $\mathrm{HCV}$ testing.

In this study, we reviewed the medical records of patients who were $\mathrm{HCV}$ antibody positive during the screening period ("newly identified cases"). We also conducted interviews to confirm history of treatment or testing history for HCV. Patients who reported that they were under treatment or had received treatment for $\mathrm{HCV}$ in the past were excluded from this study. Patients who reported positive HCV antibody or RNA test results before the screening period were also excluded.

\section{Measures}

$\mathrm{HCV}$ antibody testing was conducted by the UCLA microbiology laboratory, using standard protocols for the ADVIA Centaur XP System (Siemens Medical Solutions USA, Inc., Malven, PA). The ADVIA Centaur $\mathrm{HCV}$ assay is an in vitro diagnostic immunoassay for the qualitative determination of immunoglobulin G (IgG) antibodies to hepatitis $C$ virus in human serum and plasma using the ADVIA Centaur ${ }^{\bullet}$ System. The assay was used in conjunction with $\mathrm{HCV}$ RNA testing to determine HCV infection status. Specifically, HCV antibody reactive tests were tested for HCV RNA viral load using the $\mathrm{COBAS}^{\oplus}$ Ampliprep/ COBAS ${ }^{\bullet}$ TaqMan $^{\oplus} \mathrm{HCV}$ test (Qualitative and Quantitative, v2.0; Pleasanton, California). We collected patient demographic and clinical characteristics including age, sex, race/ethnicity, and laboratory values including liver function tests (aspartate aminotransferase (AST), alanine aminotransferase (ALT), platelet count, bilirubin levels) and, human immunodeficiency virus (HIV) infection status. In cases where these laboratory tests were not conducted on the same day as the HCV testing, we matched the laboratory testing data to the $\mathrm{HCV}$ testing data such that only testing data within 3 months of HCV antibody screening was included. We used ICD-10 codes (ICD-10 code for CKD: ICD-10-CM: N18* and ICD-10 code for DM: E11* and E10*) to determine whether patients were diagnosed with chronic kidney disease (CKD) or diabetes mellitus. These clinical markers were included in the study given the scientific literature indicating the association between CKD, diabetes, and chronic HCV infection [28-31].

\section{Statistical analysis}

We defined HCV clearance as evidence of $\mathrm{HCV}$ Ab reactivity and HCV RNA non-detectable test results in the absence of treatment. We examined differences between those who cleared their $\mathrm{HCV}$ infection and those who remained chronically infected using chi-square test, Fisher's exact test, and t-tests. We used logistic regression analysis to examine factors associated with $\mathrm{HCV}$ clearance including sociodemographic and clinical characteristics. We conducted all analyses using SAS 9.4 (NC, USA). 


\section{Human subjects}

The UCLA Institutional Review Board (IRB) approved the study activities (IRB\# 15-001226).

\section{Results}

\section{Study population characteristics}

Three hundred and eighty-six patients were considered newly identified HCV Ab Positive. Among this group, 135 patients had detectable HCV RNA indicating current active infection. Of the $251 \mathrm{HCV}$ antibody positive/HCV RNA undetectable patients, four had a false positive anti-HCV antibody test result, ten had a prior history of successful HCV treatment with clearance of $\mathrm{HCV}$ infection due to treatment (i.e., not spontaneous clearance), and 52 could not be reached for verification of their prior history of HCV treatment (Fig. 1). These 66 patients were excluded from the study resulting in a total of 320 study patients - $135 \mathrm{HCV}$ antibody positive/ HCV RNA positive (i.e., infection not cleared) and 185 HCV antibody positive/ HCV RNA negative (i.e., spontaneous clearance). The majority of the study population was born between 1945 and 1965 (62\%) and 56\% were male. Whites/Caucasians represented the single largest race/ethnicity group (64\%), followed by Black/African American (13\%) and Hispanic/Latino (9\%) (Table 1). Among our study population of newly identified HCV antibody positive patients participating in a HCV screening program $58 \%$ spontaneously cleared $\mathrm{HCV}$.

\section{Prevalence of HCV clearance}

The prevalence of HCV clearance varied by a number of demographic and clinical characteristics with HCV clearance being somewhat higher among women (63\% vs. $53 \%$; $p$ value $=0.07$, although not meeting statistical significance, and varying by race/ethnicity (Table 2 ). Specifically, we note that HCV clearance was lowest among those who identified as Black/African American (37\%).
Table 1 Demographic and clinical characteristics of newly identified HCV antibody positive patients, UCLA Health system, November 2015-September 2017

\begin{tabular}{|c|c|c|}
\hline & \multicolumn{2}{|c|}{ HCV Antibody Positive ${ }^{a}(n=320)$} \\
\hline & $n$ & $\%$ \\
\hline \multicolumn{3}{|l|}{ Age group (years) } \\
\hline $18-52$ & 99 & 31.4 \\
\hline 52-72 ("Baby Boomers") & 198 & 61.5 \\
\hline$\geq 73$ & 23 & 7.1 \\
\hline \multicolumn{3}{|l|}{ Sex } \\
\hline Male & 179 & 55.9 \\
\hline Female & 140 & 44.1 \\
\hline \multicolumn{3}{|l|}{ Race/Ethnicity } \\
\hline Asian or Pacific Islander & 5 & 1.8 \\
\hline Black or African American & 38 & 13.4 \\
\hline Hispanic or Latino & 25 & 8.8 \\
\hline Other $^{b}$ & 33 & 11.6 \\
\hline White or Caucasian & 183 & 64.4 \\
\hline \multicolumn{3}{|l|}{ Clinical Characteristics } \\
\hline Hepatitis C RNA detected & 135 & 42 \\
\hline HIV Positive & 10 & 3.1 \\
\hline Chronic Kidney Disease ${ }^{c}$ & 23 & 7.2 \\
\hline Diabetes Mellitus & 45 & 14.2 \\
\hline \multicolumn{3}{|l|}{ Laboratory Results $^{\mathrm{d}}$} \\
\hline $\mathrm{ALT}(\mathrm{U} / \mathrm{L})$ & \multicolumn{2}{|c|}{$25(17-47)$} \\
\hline $\mathrm{AST}(\mathrm{U} / \mathrm{L})$ & \multicolumn{2}{|c|}{$26(20-39)$} \\
\hline Platelet count & \multicolumn{2}{|c|}{$232(188-271)$} \\
\hline Bilirubin (mg/dL) & \multicolumn{2}{|c|}{$0.5(0.3-0.7)$} \\
\hline
\end{tabular}

Abbreviations: ALT Alanine Transaminase, AST Aspartate Transaminase ${ }^{a}$ Sum may not equal total because of missing information

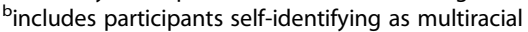
${ }^{\mathrm{C}} \mathrm{CKD}$ based on ICD-10 codes

${ }^{\mathrm{d}}$ data presented as median and interquartile range

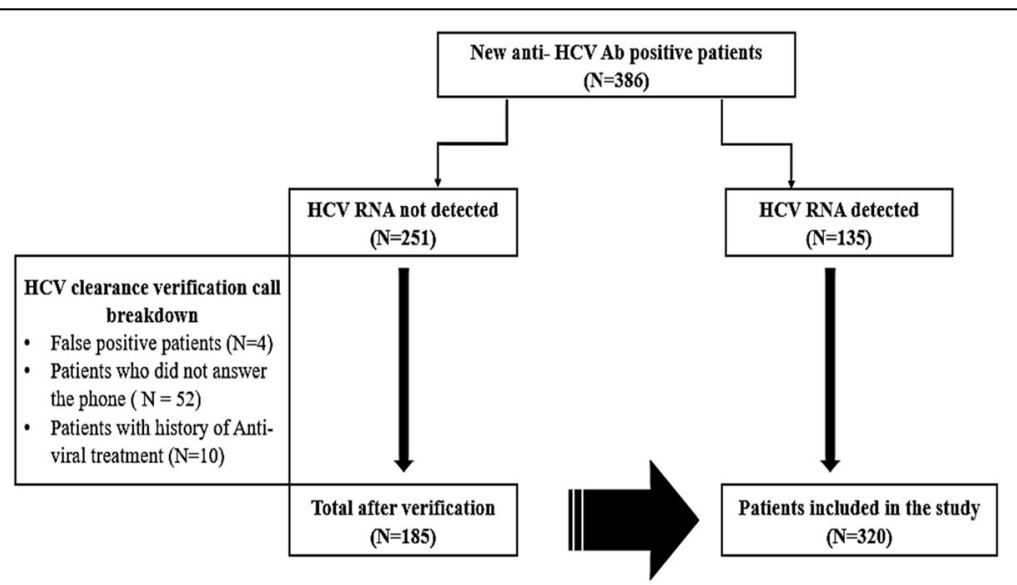

Fig. 1 HCV viral clearance population breakdown 
Table 2 Prevalence and factors associated with absence of HCV RNA among newly identified HCV antibody positive patients, UCLA Health system, November 2015-2017

\begin{tabular}{|c|c|c|c|c|c|}
\hline & HCV RI & & $P$ value & Unadjusted OR & Adjusted OR \\
\hline & $n$ & $\%$ & & I) & $(95 \%$ Cl) \\
\hline Total & 185 & 58.0 & - & - & - \\
\hline Age group (years) & & & 0.17 & & \\
\hline $18-52$ & 58 & 58.6 & & Ref & Ref \\
\hline 52-72 ("Baby Boomers") & 118 & 59.6 & & $1.04(0.64-1.70)$ & $1.35(0.75-2.39)$ \\
\hline$\geq 73$ & 9 & 39.1 & & $0.45(0.18-1.15)$ & $0.45(0.16-1.30)$ \\
\hline Sex & & & 0.07 & & \\
\hline Male & 95 & 53.1 & & Ref & Ref \\
\hline Female & 88 & 63.3 & & $1.53(0.97-2.40)$ & $1.53(0.91-2.56)$ \\
\hline Race/Ethnicity & & & 0.02 & & \\
\hline Asian & 3 & 60.0 & & $1.08(0.18-6.59)$ & $1.00(0.14-5.44)$ \\
\hline Black or African American & 14 & 36.8 & & $0.42(0.21-0.86)$ & $0.43(0.21-0.92)$ \\
\hline Hispanic or Latino & 10 & 40.0 & & $0.48(0.20-1.12)$ & $0.63(0.26-1.57)$ \\
\hline Other $^{a}$ & 27 & 82.0 & & $3.87(1.43-10.51)$ & $4.38(1.54-12.44)$ \\
\hline White or Caucasian & 106 & 58.2 & & Ref & Ref \\
\hline Clinical Characteristics & & & & & \\
\hline HIV Positive & & & 0.33 & & \\
\hline Yes & 4 & 40.0 & & $0.48(0.13-1.73)$ & - \\
\hline No & 180 & 58.3 & & Ref & \\
\hline Chronic Kidney Disease $^{b}$ & & & 0.06 & & \\
\hline Yes & 9 & 39.1 & & $0.45(0.19-1.06)$ & $0.37(0.14-1.03)$ \\
\hline No & 173 & 59.0 & & Ref & Ref \\
\hline Diabetes Mellitus & & & 0.76 & & \\
\hline Yes & 25 & 55.6 & & $0.91(0.48-1.71)$ & - \\
\hline No & 157 & 57.9 & & Ref & \\
\hline
\end{tabular}

Abbreviations: $O R$ odds ratio, $\mathrm{Cl}$ confidence interval

ancludes participants self-identifying as multiracial

${ }^{b}$ CKD based on ICD-10 codes

\section{Factors associated with spontaneous HCV clearance}

After adjusting for age and sex, we found that race/ethnicity was independently associated with spontaneous HCV clearance. Those who identified as African American/ Black had a $57 \%$ decreased odds of $\mathrm{HCV}$ clearance as compared to Whites [adjusted odds ratio $(\mathrm{aOR})=0.43$; $95 \%$ confidence interval $(\mathrm{CI})=0.21-0.92$ ) (Table 2 ). Moreover, those diagnosed with chronic kidney disease $(\mathrm{aOR}=$ 0.34; 95\% CI 0.14-1.03) had a tendency to decreased likelihood of spontaneous HCV clearance.

\section{Discussion}

We investigated the frequency of and factors associated with spontaneous $\mathrm{HCV}$ viral clearance among patients participating in a hepatitis $C$ screening program at a large urban health system in Los Angeles. In this study, $58 \%$ of patients with newly identified infection had evidence of $\mathrm{HCV}$ viral clearance. It should be noted that we only included newly identified HCV Ab positive patients with prior testing and verified treatment history through both chart review and patient interviews, which may explain the difference compared to other published studies [1, 4, 30]. Among our patient population, spontaneous $\mathrm{HCV}$ viral clearance varied by race/ethnicity and was somewhat less likely to occur among those with chronic kidney disease (CKD).

Consistent with previous studies, clearance was greater among white patients compared to their black counterparts $[1,4]$. Previous studies on genetic markers perhaps could explain the increased proportion of spontaneous viral clearance among non-black patients [10, 32-34]. Key modification with natural killer (NK) cells populations, HLA class II alleles and IL28B polymorphism have been suggested to predict the relationship between ethnic characteristics and HCV clearance [1, 32, 35-37]. A study conducted by Golden-Mason et al. proposed 
that the proportion of NKp46 expression was lower among African Americans compared to their white counterparts $[1,35]$. NK cells are known to be the immune system's first line of defense against viral pathogens [38]. NK cells do this work by eliminating virus-infected cells directly via cytolytic mechanisms or indirectly by secreting cytokines [38, 39]. Moreover, HLA type II alleles have been suggested to have some conflicting roles however, research suggests their role with HCV clearance includes the fact that African Americans have weaker HCV specific immunity [37]. Furthermore, IL28B polymorphism is known to be the strongest host gene predictor of HCV clearance. Previous studies discuss that IL28B allele rs12979860 were less likely to be observed among persons of African descent compared to European descent. Study by Ge et al., outlines the fact that HCV clearance occurred in $36.4 \%$ among non-blacks compared to $9.3 \%$ among black persons [10]. The suggested mechanism along with previous studies provides some evidence that NK cells and other genetic markers can play a protective role in patients exposed to hepatitis C. However, despite studies on predictors of $\mathrm{HCV}$ clearance, the association between ethnic characteristics and HCV viral clearance is not well understood and should be explored further.

Our study also found that patients with chronic kidney disease were somewhat less likely to clear $\mathrm{HCV}$ infection compared to those without chronic kidney disease. Due to several clinical implications, in 2017, the Kidney Disease Improving Global Outcome organization drafted specific guidelines to increase HCV screening among chronic kidney disease patients [40]. Earlier studies propose that HCV infection may influence the development of chronic kidney disease by stimulating a series of immune reactions that targets the kidney, which ultimately leads to glomerulonephritis [29, 41]. According to Azmi et al., the mechanism related to glomerulonephritis and $\mathrm{HCV}$ infection is known to be immune-complex mediated. Researchers believe that deposition of the immune complexes can trigger glomerulonephritis [41]. Overall, we also observed that $\mathrm{HCV}$ was associated with chronic kidney disease, although from our cross-sectional study we cannot determine causation.

There are a number of limitations in our study including: (1) our modest sample size limits our ability for extensive analyses; (2) given the lack of information on the precise timing of $\mathrm{HCV}$ exposure and $\mathrm{HCV}$ infection we are unable to determine time to HCV clearance; (3) exclusion of patients whose $\mathrm{HCV}$ clearance status could not be verified could have biased our estimates of $\mathrm{HCV}$ clearance; (4) lack of information on viral subtype limited our ability to determine whether HCV subtype is associated with clearance; and (5) we included only "newly identified cases" of $\mathrm{HCV}$, excluding patients with previous $\mathrm{HCV}$ positive results, thus our results are not generalizable to other populations nor do they represent an unbiased population estimate of $\mathrm{HCV}$ clearance. Finally, we were unable to verify a specific Race/Ethnicity for patients included in the "Other" category during data extraction, which could have potentially affected our conclusions on the associations between $\mathrm{HCV}$ clearance and Race/ethnicity. Despite those limitations, this is one of a few studies exploring difference in HCV spontaneous clearance among a screening population, with rigorous strategies employed to exclude those with previous treatment history or false positive testing status.

Future studies should explore on the social regulation of gene expression. According to Cole et al., social regulation of gene expression is a conceptual relationship between genes and social world [42]. Recent studies suggest clear associations between social factors and the regulations of the human genome [42-44]. Perhaps the decreased expression of NKp46 or other genetic factors observed among black patients can be attributed to their exposure to poor environmental, social and economic conditions. Asking and attempting to answer those questions might enable a better understanding of what drives genetic differences at the molecular level.

\section{Conclusions}

Overall, this study confirms a higher frequency of $\mathrm{HCV}$ spontaneous clearance. In addition, this study identified certain subgroups more likely to clear $\mathrm{HCV}$ infection. Individuals who are at greater risk for $\mathrm{HCV}$ infection such as those who identify as African American and patients with chronic kidney disease should be prioritized for HCV screening and treatment initiatives.

\section{Abbreviations}

ALT: Alanine Aminotransferase; AST: Aspartate Aminotransferase;

CKD: chronic kidney disease; HCV: Hepatitis C; HIV: Human Immunodeficiency Virus; ICD-10: International classification of diseases; UCLA: University of

California, Los Angeles

\section{Acknowledgements \\ The authors wish to thank you Youssef Challita and Dr. El-Kabbany for reviewing draft of the manuscript.}

\section{Authors' contributions}

All authors have read and approved the manuscript before submission. MK data acquisition, drafting, writing manuscript and critically thinking about manuscript content. MJ - results interpretation, data/statistical analysis, and critically thinking about manuscript content. KC- Provided valuable insights for revising manuscript. CS - provided valuable insights for revising the manuscript and interpretation. DH - Data acquisition, drafting manuscript. SR - Data acquisition specifically calling and verifying HCV treatment history/ HCV spontaneous clearance. YB- data/statistical analysis. SS - UCLA Pledger Liver institute attending and provided valuable insights for revising manuscript. JDK - Principal investigator and provided valuable insights in obtaining funding, study design, analysis and manuscript preparation.

\section{Funding}

This work was supported in part by a grant to Dr. Klausner from Gilead Sciences, Incorporated as Frontlines of communities in the United States (FOCUS) program partners (20173211). Gilead Sciences had no role in the study design, analysis, interpretation of the data or manuscript preparation. 


\section{Availability of data and materials}

All data generated or analyzed during this study are available from the principal investigator on reasonable request.

\section{Ethics approval and consent to participate}

Study activities were reviewed by the UCLA International Review Board (IRB) under IRB\# 15-001226.

\section{Consent for publication}

Not applicable.

\section{Competing interests}

KWC has received a research grant to the institution from Merck Sharpe \& Dohme, Corp. The other authors do not have a commercial or other association that might pose a conflict of interest.

\section{Author details}

'Department of Medicine, Division of Infectious Diseases, University of California Los Angeles, 10920 Wilshire Blvd. Suite 350 Room 40, Los Angeles, CA 90024, USA. ${ }^{2}$ Department of Epidemiology, Fielding School of Public Health, University of California Los Angeles, Los Angeles, USA. ${ }^{3}$ Department of Medicine and Surgery, David Geffen School of Medicine, University of California Los Angeles, Los Angeles, USA.

Received: 17 August 2018 Accepted: 26 June 2019

Published online: 15 July 2019

\section{References}

1. Aisyah DN, et al. Assessing hepatitis C spontaneous clearance and understanding associated factors-a systematic review and meta-analysis. J Viral Hepat. 2018;25(6):680-98.

2. Seaberg EC, et al. Spontaneous clearance of the hepatitis C virus among men who have sex with men. Clin Infect Dis. 2015;61(9): $1381-8$

3. Newsum AM, et al. Spontaneous clearance of hepatitis $C$ virus infection among human immunodeficiency virus-infected men who have sex with men. Open Forum Infect Dis. 2017;4(2):ofx090.

4. Micallef JM, Kaldor JM, Dore GJ. Spontaneous viral clearance following acute hepatitis C infection: a systematic review of longitudinal studies. J Viral Hepat. 2006;13(1):34-41.

5. Abdelwahab SF. Cellular immune response to hepatitis-C-virus in subjects without viremia or seroconversion: is it important? Infect Agent Cancer. 2016;11:23.

6. Lemon SM. Induction and evasion of innate antiviral responses by hepatitis C virus. J Biol Chem. 2010;285(30):22741-7.

7. Grebely J, et al. Genetics of spontaneous clearance of hepatitis C virus infection: a complex topic with much to learn. Hepatology. 2014;60(6): 2127-8

8. Post JJ, et al. Clearance of hepatitis C viremia associated with cellular immunity in the absence of seroconversion in the hepatitis $C$ incidence and transmission in prisons study cohort. J Infect Dis. 2004;189(10):1846-55.

9. Ge D, et al. Genetic variation in IL28B predicts hepatitis C treatment induced viral clearance. Nature. 2009;461(7262):399-401.

10. Thomas DL, et al. Genetic variation in IL28B and spontaneous clearance of hepatitis C virus. Nature. 2009;461(7265):798-801.

11. Shi $X$, et al. IL28B genetic variation is associated with spontaneous clearance of hepatitis $C$ virus, treatment response, serum IL-28B levels in Chinese population. PLoS One. 2012:7(5):e37054

12. Grebely J, et al. The effects of female sex, viral genotype, and IL28B genotype on spontaneous clearance of acute hepatitis $C$ virus infection. Hepatology. 2014;59(1):109-20

13. Grebely J, et al. Factors associated with spontaneous clearance of hepatitis C virus among illicit drug users. Can J Gastroenterol. 2007; 21(7):447-51.

14. Tsui Jl, et al. The effects of alcohol on spontaneous clearance of acute hepatitis $C$ virus infection in females versus males. Drug Alcohol Depend. 2016:169:156-62.

15. Sacks-Davis $R$, et al. Hepatitis $C$ virus reinfection and spontaneous clearance of reinfection--the InC3 study. J Infect Dis. 2015;212(9): 1407-19.
16. Zhang $\mathrm{M}$, et al. Correlates of spontaneous clearance of hepatitis $\mathrm{C}$ virus among people with hemophilia. Blood. 2006;107(3):892-7.

17. Busch MP, et al. Correlates of hepatitis C virus (HCV) RNA negativity among HCV-seropositive blood donors. Transfusion. 2006:46(3):469-75.

18. Garten RJ, et al. Factors influencing a low rate of hepatitis $C$ viral RNA clearance in heroin users from southern China. World J Gastroenterol. 2008; 14(12):1878-84.

19. Melendez-Morales $\mathrm{L}$, et al. Chronic hepatitis B and other correlates of spontaneous clearance of hepatitis C virus among HIV-infected people with hemophilia. AIDS. 2007;21(12):1631-6.

20. Bulteel $\mathrm{N}$, et al. Factors associated with spontaneous clearance of chronic hepatitis C virus infection. J Hepatol. 2016;65(2):266-72.

21. Deutsch $\mathrm{M}$, et al. Clinical characteristics, spontaneous clearance and treatment outcome of acute hepatitis C: a single tertiary center experience. Saudi J Gastroenterol. 2013:19(2):81-5.

22. Konerman MA, et al. Impact of an electronic health record alert in primary care on increasing hepatitis c screening and curative treatment for baby boomers. Hepatology. 2017;66(6):1805-13.

23. Geboy $\mathrm{AG}$, et al. High hepatitis $\mathrm{C}$ infection rate among baby boomers in an urban primary care clinic: results from the HepTLC initiative. Public Health Rep. 2016;131(Suppl 2):49-56.

24. Younossi ZM, et al. Implementation of baby boomer hepatitis $C$ screening and linking to care in gastroenterology practices: a multi-center pilot study. BMC Gastroenterol. 2016;16:45

25. Turner BJ, et al. Implementing hospital-based baby boomer hepatitis C virus screening and linkage to care: strategies, results, and costs. J Hosp Med. 2015;10(8):510-6.

26. Chou R, Cottrell EB, Wasson N, Rahman B, Guise J. Screening for Hepatitis C Virus Infection in Adults: A Systematic Review for the U.S. Preventive Services Task Force. Ann Intern Med. 2013:158:101-8. https://doi.org/10. 7326/0003-4819-158-2-201301150-00574.

27. Castrejon $\mathrm{M}$, et al. Implementation of a large system-wide hepatitis $\mathrm{C}$ virus screening and linkage to care program for baby boomers. Open Forum Infect Dis. 2017:4(3): ofx109

28. Barsoum RS, William EA, Khalil SS. Hepatitis C and kidney disease: a narrative review. J Adv Res. 2017:8(2):113-30.

29. Kusnir J, Roth D. Direct-acting antiviral agents for the hepatitis C virusinfected chronic kidney disease population: the Dawn of a new era. Semin Dial. 2016;29(1):5-6.

30. Dai $C Y$, et al. Chronic hepatitis $C$ infection is associated with insulin resistance and lipid profiles. J Gastroenterol Hepatol. 2015;30(5): 879-84.

31. Jadoul $M$, Martin P. Hepatitis C treatment in chronic kidney disease patients: the kidney disease improving global outcomes perspective. Blood Purif. 2017:43(1-3):206-9.

32. Zheng MH, et al. Interleukin-28B rs12979860C/T and rs8099917T/G contribute to spontaneous clearance of hepatitis $C$ virus in Caucasians. Gene. 2013;518(2):479-82.

33. Jimenez-Sousa MA, et al. Meta-analysis: implications of interleukin-28B polymorphisms in spontaneous and treatment-related clearance for patients with hepatitis C. BMC Med. 2013;11:6.

34. Sarkar M, et al. Racial/ethnic differences in spontaneous HCV clearance in HIV infected and uninfected women. Dig Dis Sci. 2013; 58(5):1341-8

35. Golden-Mason $L$, et al. Race- and gender-related variation in natural killer p46 expression associated with differential anti-hepatitis $C$ virus immunity. Hepatology. 2012:56(4):1214-22.

36. Shah DP, et al. Demographics, socio-behavioral factors, and drug use patterns: what matters in spontaneous HCV clearance? J Med Virol. 2012; 84(2):235-41.

37. Rosen $H R$, et al. Selective decrease in hepatitis $C$ virus-specific immunity among African Americans and outcome of antiviral therapy. Hepatology. 2007;46(2):350-8.

38. Cooper MA, Fehniger TA, Caligiuri MA. The biology of human natural killercell subsets. Trends Immunol. 2001;22(11):633-40.

39. Robertson MJ, Ritz J. Biology and clinical relevance of human natural killer cells. Blood. 1990;76(12):2421-38

40. (KDIGO), K.DIGO Clinical Practice guideline on the prevention, diagnosis, evaluation, and treatment of hepatitic C in CKD. 2017 [cited 2018 April 12]: Available from: https://kdigo org/guidelines/ hepatitis-c-in-ckd/. 
41. Azmi AN, Tan SS, Mohamed R. Hepatitis C and kidney disease: an overview and approach to management. World J Hepatol. 2015;7(1): 78-92.

42. Cole SW. Social regulation of human gene expression: mechanisms and implications for public health. Am J Public Health. 2013;103(Suppl 1):S84-92.

43. Cole SW, et al. Social regulation of gene expression in human leukocytes. Genome Biol. 2007;8(9):R189.

44. Cole SW. Social regulation of human gene expression. Curr Dir Psychol Sci. 2009;18(3):132-7.

\section{Publisher's Note}

Springer Nature remains neutral with regard to jurisdictional claims in published maps and institutional affiliations.

Ready to submit your research? Choose BMC and benefit from:

- fast, convenient online submission

- thorough peer review by experienced researchers in your field

- rapid publication on acceptance

- support for research data, including large and complex data types

- gold Open Access which fosters wider collaboration and increased citations

- maximum visibility for your research: over $100 \mathrm{M}$ website views per year

At $\mathrm{BMC}$, research is always in progress.

Learn more biomedcentral.com/submissions 